\title{
EFFECT OF LOW-LEVEL LASER THERAPY ON PAIN EXPERIENCED DURING LEVELING AND ALIGNMENT OF LOWER ANTERIOR TEETH: A RANDOMIZED CONTROLLED CLINICAL STUDY
}

\author{
Tharwat Osman El Shehawy*, Farouk Ahmed Hussein**, Akram Abbbas EI Awady***
}

\begin{abstract}
Objective: This randomized controlled clinical study investigated the effect of a $635 \mathrm{~nm}$ Gallium-Aluminum-Arsenide (GaAl-As) laser on pain perception during the leveling and alignment of lower anterior teeth. Subjects and Methods: Twenty eight orthodontic patients, 17 females and 11 males, were randomly selected who underwent leveling and alignment through a non-extraction approach. They were randomly divided according to into two groups: non-laser group and low-level laser therapy (LLLT) group. Both groups utilized the same leveling 0.012 inch Ni-Ti arch wires. The laser group was exposed to Ga-Al-As semiconductor diode laser with $635 \mathrm{~nm}$ wavelength, $6.5 \mathrm{~J} / \mathrm{cm}^{2}$ energy density, for 10 seconds on 10 points distributed over the labial and lingual aspects of each root of the lower anterior teeth. This was applied immediately after archwire insertion and then at days 3,7,14, 28 of the first month. Each patient was provided with a Visual Analog Scale (VAS) to record the pain score at 4 hours, 6 hours, 24 hours, 3 days, 7 days, and 28 days. Results: In both laser and non-laser groups, there is a statistically non-significant increase of pain measurements at 6 and 24 hours and a non-significant decrease in mean of pain measurements after day 3. Conclusions: The LLLT, with current parameters and protocol, has a negligible effect on pain experienced during initial orthodontic leveling and alignment stage.
\end{abstract}

Keywords: Low-Level Laser Therapy, Orthodontic Leveling and Alignment, Pain, Visual Analog Scale

\section{INTRODUCTION}

Orthodontic therapy is essential for functional and several aesthetic rehabilitation therapies of the stomatognathic system. It is known that application of orthodontic force to the dental system stimulates a transient inflammatory process mediated by inflammatory mediators, with no pathological condition producing some sort of pain ${ }^{(1)}$.Doubtless orthodontic pain is one of the unwanted side effects given a great concern among orthodontic patients directing them to their withdrawal from the treatment.Orthodontic pain is described as discomfort, dull pain, and hypersensitivity in affected teeth ${ }^{(2)}$, it usually reaches its peak 24 hours after wire engagement, and begins to reduce 72 hours after wire engagement ${ }^{(3)}$.

Several methods have shown a reduction of the discomfort caused by pain during tooth movement such as anti-inflammatory medication ${ }^{(4)}$, low-level laser therapy (LLLT), however, the secondary effects of the administration of non-steroidalantiinflammatory drugs (NSAID) may affect the rate of tooth movement. ${ }^{(4)}$

* 1Dentist, Ministry of Health, MSc student, Department of Orthodontics, Faculty of Dental Medicine (Boys), AlAzhar University, Cairo, Egypt

** Associate Professor \& Acting Chairman, Department of Orthodontics, Faculty of Dental Medicine (Boys), AlAzhar University, Cairo, Egypt

*** Professor, Department of Oral Medicine \& Diagnosis \&Radiology, Faculty of Dental Medicine (Boys), Al-Azhar University, Cairo, Egypt 
Low-level laser therapy (LLLT) has an energy output that is low enough so as not to cause the temperature of the treated tissues to rise above $36.5^{\circ} \mathrm{C}$ or normal body temperature. The LLLT has been introduced into medicine and dentistry for various clinical practices for its bio-stimulatory effect which contributed to wound healing, muscle relaxation, nerve regeneration, collagen synthesis, fibroblast proliferation, acceleration of bone regeneration, reduction of inflammation, to improve blood circulation and increase cell activity. In the field of orthodontics, researchers proposed a positive effect of LLLT in managing orthodontic pain and increasing bone deposition in midpalatal suture during rapid maxillary expansion in animals ${ }^{(5-8)}$.

Because of easy application and noninvasive use of LLLT in addition to its limited side effects and fewer contraindications, many studies used it to control pain resulted from orthodontic tooth movement reporting that LLLT was able to control pain during orthodontic tooth movement, however, other studies indicate that laser cannot ${ }^{(3)}$. The debate continues, as conflicting conclusions were reached in recent systematic reviews regarding clinical trials of LLLT therapy with orthodontic tooth movement (OTM), it appears that the findings reports revealed controversial results the effect of LLLT on orthodontic pain ${ }^{(9)}$. The extensive variability in the experimental designs and laser specs e.g. wavelength, power output, energy density, mode, duration, and frequency of laser applications is a major contributor factor to the existing conflicting conclusions and presents a challenge that should be considered $^{(9)}$.

Since few studies are available investigated multiple doses of LLLT through leveling and alignment phase of orthodontic treatment ${ }^{(10)}$, the aim of the current study was directed to evaluate the effect of continuous multiple doses of LLLT on orthodontic pain during leveling and alignment of the lower anterior teeth. The hypothesis of the study was supposed that LLLT could reduce pain during leveling and alignment of the lower anterior teeth.

\section{SUBJECTS AND METHODS}

This randomized controlled clinical trial was performed from January 2018 to July 2018 on a total sample of 28 patients, 17 females and 11 males were selected from outpatient clinic, Department of Orthodontics, Faculty of Dental Medicine (Boys), Al-Azhar University, Cairo, Egypt. Institutional Review Board and Ethical Committee of AlAzhar University reviewed and approved the study protocol. All patients and/or their parents who agreed to participate in this research signed an informed consent document that authorized their data to be used for research purposes. Based on the previous studies ${ }^{(10-13)}$, a power analysis using G*Power software (version 3.1.9.2; Universitat Dusseldorf, Dusseldorf, Germany) estimated that the sample size of 28 patients ensured more than $80 \%$ power to detect significant differences at a 0.05 significance level. Theywere randomly divided into two groups according to the intervention into laser group and non-laser group (Fig.1).

All patients were selected according the following inclusion criteria: Class I malocclusion, with moderate mandibular crowding, orthodontic treatment with no extraction on the mandibular arch, all mandibular teeth erupted (third molars not included), and no spaces in the mandibular arch and the following exclusion criteria were considered: use of analgesics, treatment requires extractions of any tooth, impacted or unerupted permanent teeth, treatment with intraoral or extraoral removable appliances, patients with cleft lip and palate, anomalies, and syndromes.

Every participant was treated with the same Roth pre-adjusted metallic brackets (3M Unitek, Monrovia, Calif), leveling and alignment for both groups were carried out starting with 0.012-inch Ni-Ti archwire (Ortho Organizer ${ }^{\circledR}$ Super Elastic TitaniumArchwiress, USA) for the $1^{\text {st }}$ month and ligated with elastomeric ligatures. Laser group received low-level laser therapy (LLLT) via Ga-AlAs diode laser (Smart ${ }^{\mathrm{TM}}$ PRO, Lasotronix, Poland) with a wavelength of $635 \mathrm{~nm}$, energy density of $6.5 \mathrm{~J} \backslash \mathrm{cm}^{2}$, power output $20 \mathrm{~mW}$ (Fig.2a). 


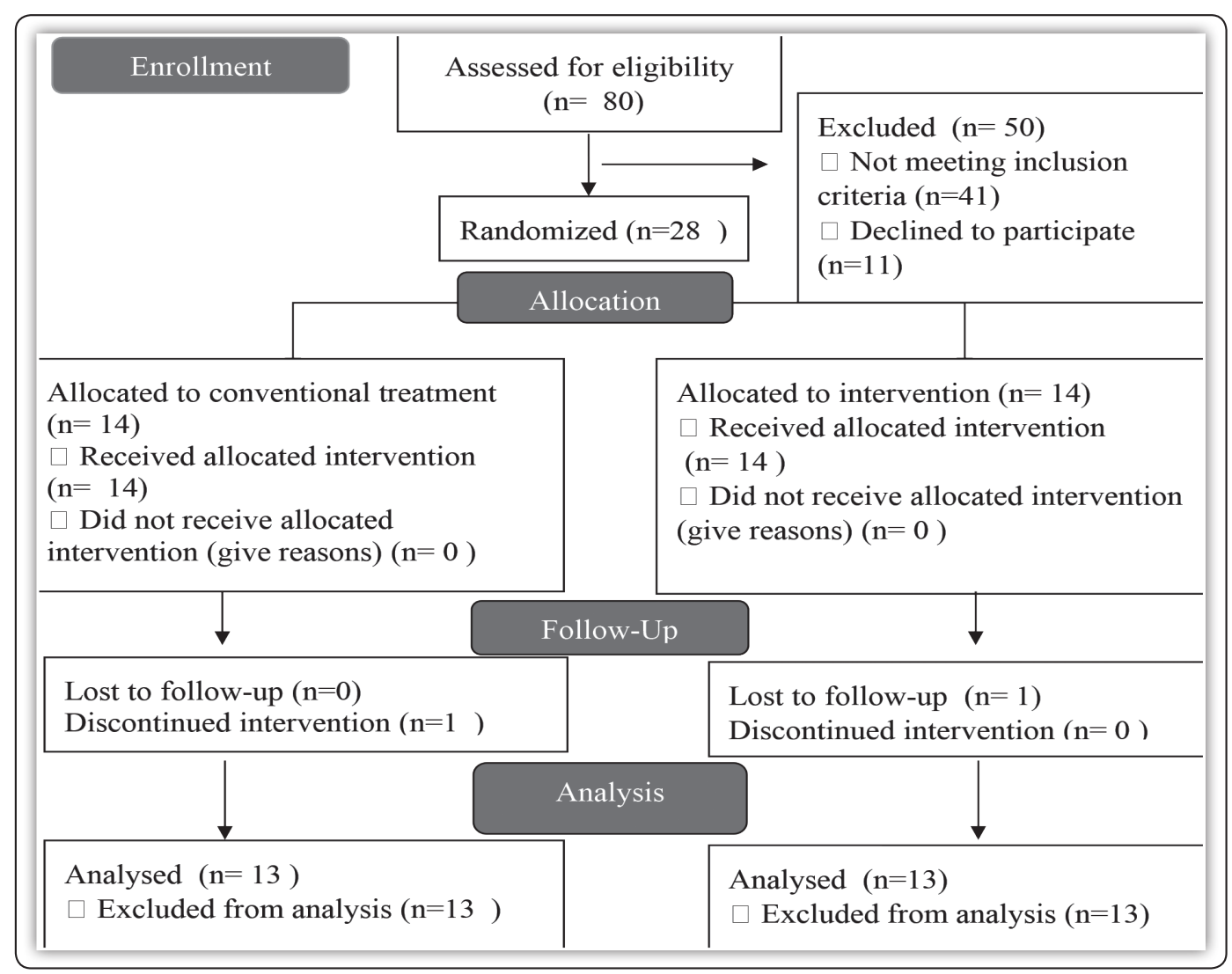

FIG (1) CONSORT Flow Diagram.

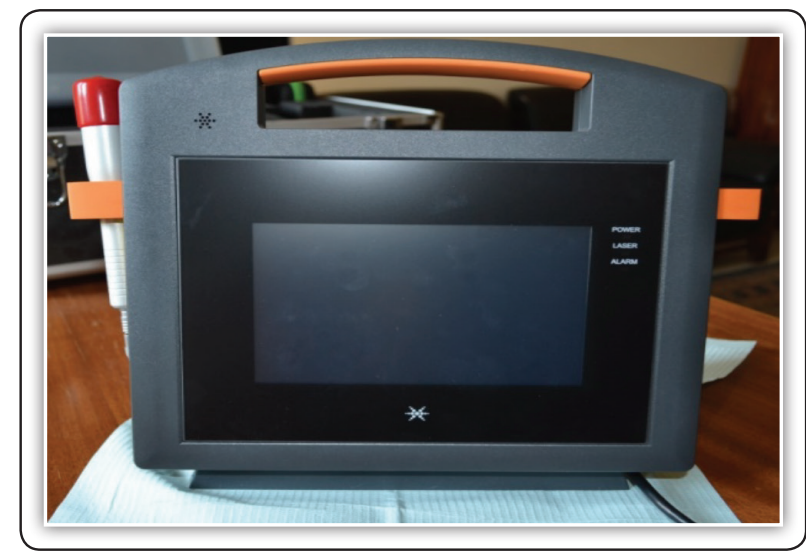

FIG (2a) Gallium Aluminum Arsenide semiconductor diode laser equipment used in the study.

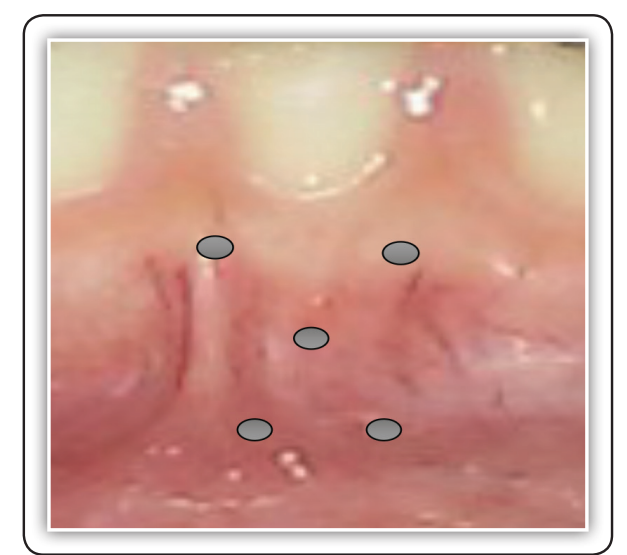

FIG (2b) Points of application of LLLT from the labial aspect. 
This was applied on 10 points on each root of the lower anterior teeth 5 labial and 5 lingual (Fig.2b) for $10 \mathrm{sec}(2$ points: mesial and distal to the apical area and 2 points: mesial and distal to the cervical area and one on the middle of the root). These parameters and protocol of application delivered a $0.2 \mathrm{~J}$ per point, $2 \mathrm{~J}$ per tooth and 12 Joules as a total dose of energy was delivered to the lower anterior segment per session. This was doneon days $0,3,7$ and 14 starting from the day of the archwire placement.

All patientsrequested to mark pain intensity represented from 0 to 10 on the Visual Analogue Scale (VAS) at 4 hours, 6 hours , 24 hours, 3 days, 1 week, and 28 days $^{(11)}$ (Fig.3), using the terms no pain (0) and the highest pain (10) perceived over first month during incising and rest.

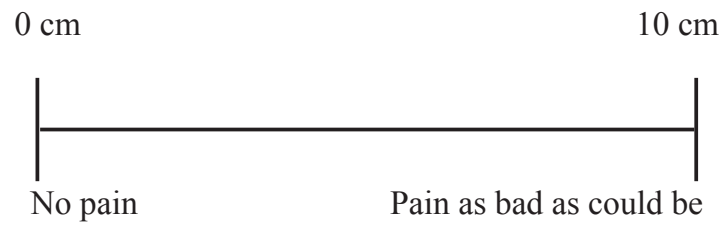

Fig. (3) Visual analog scale (VAS)

\section{Statistical Analysis}

All VAS scores were statistically analyzed using the SPSS (Statistical Package for Social Sciences (SPSS, version 22, Inc, Chicago, III) program. Mann Whitney test was used to compare pain scores between groups.

\section{RESULTS}

Although 2 patients ( 1 male and 1 female) were dropped out due to either missing appointments of laser application or repeated breakage of the orthodontic appliance the remaining 26 patients (16 females and 10 males ) had completed the course of this study.

A comparison between the two studied groups (table 1) during incising shows a statistically nonsignificant increase at 6 and 24 hours and decrease in mean degree of pain measurements after day 3 .
A comparison between the two studied groups (table 2) during restshows a statistically nonsignificant increase at 6 and 24 hours and decrease in mean degree of pain measurements after day 3 .

TABLE (1) Comparison between the two studied groups during incising

\begin{tabular}{|c|c|c|c|c|c|c|c|}
\hline \multirow{2}{*}{} & \multicolumn{2}{|c|}{$\begin{array}{c}\text { Non-Laser } \\
(\mathbf{n = 1 3})\end{array}$} & \multicolumn{2}{|c|}{$\begin{array}{c}\text { laser } \\
(\mathbf{n = 1 3})\end{array}$} & \multirow{2}{*}{ U } & p \\
\cline { 2 - 5 } & Mean & \pm SD & Mean & \pm ISD & & \\
\hline Incising & 4.50 & 0.71 & 3.30 & 1.42 & 46.0 & 0.569 \\
\hline $4 \mathrm{hr}$ & 5.30 & 0.95 & 4.90 & 1.66 & 44.0 & 0.674 \\
\hline 6hr & 5.20 & 1.32 & 4.80 & 1.23 & 43.0 & 0.543 \\
\hline 3 Day & 3.90 & 0.57 & 3.60 & 1.58 & 41.0 & 0.651 \\
\hline 7Day & 2.60 & 1.29 & 2.10 & 2.27 & 44.0 & 0.684 \\
\hline 28 days & 2.10 & 1.07 & 1.60 & 1.73 & 43.0 & 0.631 \\
\hline
\end{tabular}

U: Mann Whitney test

$p$ : p-value for comparing between the studied groups

*: Statistically significant at $p \leq 0.05$

Table (2): Comparison between the two studied groups during rest

\begin{tabular}{|c|c|c|c|c|c|c|}
\hline & \multicolumn{2}{|c|}{$\begin{array}{l}\text { Non-Laser } \\
(\mathrm{n}=13)\end{array}$} & \multicolumn{2}{|c|}{$\begin{array}{c}\text { laser } \\
(n=13)\end{array}$} & \multirow[t]{2}{*}{$\mathbf{U}$} & \multirow{2}{*}{$\mathbf{p}$} \\
\hline & Mean & \pm SD & Mean & \pm SD & & \\
\hline \multicolumn{7}{|l|}{ Rest } \\
\hline $4 \mathrm{hr}$ & 4.70 & 1.49 & 3.90 & 1.45 & 36.50 & 0.315 \\
\hline $6 \mathrm{hr}$ & 5.0 & 1.56 & 3.80 & 1.40 & 28.50 & 0.105 \\
\hline $24 \mathrm{hr}$ & 4.70 & 1.57 & 4.60 & 2.22 & 40.0 & 0.481 \\
\hline 3Day & 2.10 & 1.66 & 1.70 & 1.0 & 32.50 & 0.195 \\
\hline 7Day & 0.90 & 0.26 & 0.60 & 0.20 & 33.50 & 0.145 \\
\hline 28 days & 0.60 & 0.40 & 0.60 & 0.40 & 29.0 & 0.123 \\
\hline
\end{tabular}

U: Mann Whitney test

$p$ : p-value for comparing between the studied groups

*: Statistically significant at $p \leq 0.05$ 


\section{DISCUSSION}

It is apparent that almost all patients submitted to fixed orthodontic treatment suffer some type of discomfort, considering the separation of teeth for posterior orthodontic banding or after the archwire insertion, which may also discourage them to continue the treatment, or even giving up at the beginning of the process ${ }^{(10)}$. The perception of pain varies considerably from patient to patient. Thus, pain is a highly subjective sensation and due to this fact, it becomes very difficult to quantify it in scientific researches ${ }^{(10)}$.

In many studies, Visual Analogue Scale (VAS) was verified to be sensitive to treatment effects ${ }^{(14-16)}$. It was found to correlate favorably with other selfreporting indicators of pain severity ${ }^{(14)}$. Furthermore, the difference in pain severity measured by VAS at two different points of time reflects the actual difference in pain level, which seems to be the main benefit of this method compared to others ${ }^{(17)}$.

Normally, pain during orthodontic treatment is noticeable, mainly in the first three days, reaching its maximum level in 24 hours, and decreasing after the third day of activation ${ }^{(10)}$.

According to the current results, the null hypothesis of the study was rejected. The present study employed a wavelength of $653 \mathrm{~nm}$, power output $20 \mathrm{~mW}$, energy density $6.5 \mathrm{~J} / \mathrm{cm}^{2}$. However, the outcomes obtained from the present study, demonstrated that there is a non-significant decrease in pain between the nonlaser and laser groups. This is in accordance with several previous studies ${ }^{(3,18-23)}$, for example,Abtahi et al, AlSayed et al, Furquim et al, Lim et al, Angelieri et al, Dalaie et al, Heraviet $\mathrm{al}^{(3,18-23)}$.

On the other hand, LLLT approved a positive effect toward reduction of pain perception during OTM ${ }^{(7,13,24-35)}$. When Artés-Ribas et al, Nóbrega et al, Almallah et al, used a wavelength of 830 $\mathrm{nm}$ in conjunction with elastomeric separators placement $^{(24,25,30)}$, it was effective to control pain experienced, which comes against the current study findings. This could be due to the use of a higher wavelength. In addition, the higher dosage $12 \mathrm{~J}^{(25)}$, $5 J^{(30)}$, and higher energy density $16 \mathrm{~J} / \mathrm{cm}^{2(24)}$, could play a role in such dissimilar results.

After first and final archwires placement Tortamano et al, and Dominguez et al, found that LLLT with the same wavelength of $(830 \mathrm{~nm})$ had a positive effect in pain reduction when used with energy density $5 \mathrm{~J} / \mathrm{cm}^{2}$ per tooth for $16 \mathrm{~s} /$ point $^{(33)}$, and energy $4.4 \mathrm{~J}$ per tooth, ${ }^{(34)}$. These findings come against the current study, which could be due to the final higher dose delivered to each tooth.

However, Eslamian et al ${ }^{(27)}$, used a wavelength of $810 \mathrm{~nm}$ and energy density $2 \mathrm{~J} / \mathrm{cm}^{2}$ per point after elastomeric separators placemen, Farias et $\mathrm{al}^{(28)}$ used the same parameters but in the early stages of orthodontic treatment. while Bayani et $\mathrm{al}^{(31)}$ used the same wavelength in the early stages of orthodontic treatment in conjunction with higher energy density $3.6 \mathrm{~J} / \mathrm{cm}^{2}$. All of them found a significant decrease in pain perception after the LLLT application.

The controversy continued, when Qamruddin et $\mathrm{al}^{(13)}$, proved the positive effect of LLLT in pain reduction when used with higher parameters and doses than the current study. It was evident when applied a wavelength of $940 \mathrm{~nm}$ with a total energy of $12 \mathrm{~J}$ per tooth after elastomeric separation placement, ${ }^{(7)}$. in addition, when applied the same wavelength in combination with energy density of $75 \mathrm{~J} / \mathrm{cm}^{2}$ per tooth in a single dose after every archwire placement during leveling and alignment stage $^{(13)}$.

Marini et $\mathrm{al}^{(29)}$, Deshpande et $\mathrm{al}^{(32)}$, Bicakci et $\mathrm{al}^{(26)}$, Doshi-Mehta, and Bhad-Patil ${ }^{(35)}$ reduced the pain sensation with the help of LLLT. They used higher wavelengths of $910 \mathrm{~nm}$ with a total energy of $54.4 \mathrm{~J}$ per tooth after elastomeric separation ${ }^{(29)}$, $904 \mathrm{~nm}$ with output $10 \mathrm{~mW}$ for $120 \mathrm{~s} /$ side during

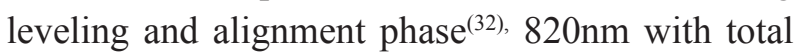
energy $1 \mathrm{~J}$ per tooth after elastomeric separators placement $^{(26)}$ and $800 \mathrm{~nm}$ with $8 \mathrm{~J}$ per tooth after activation during canine retraction, ${ }^{(35)}$ respectively. 


\section{CONCLUSION}

Based on the current results, it could be concluded that the LLLT, with current parameters and protocol, has a negligible effect on pain experienced during initial orthodontic leveling and alignment stage.

\section{REFERENCES}

1. Garlet TP, Coelho U, Silva JS, Garlet GP.Cytokine expression pattern in compression and tension sides of the periodontal ligament during orthodontic tooth movement in humans. Eur J Oral Sci 2007;115:355-62.

2. Kavaliauskiene A, Smailiene D, Buskiene I, Keriene D.Pain and discomfort perception among patients undergoing orthodontic treatment: results from one month follow-up study. Stomatologija 2012;14:118-25.

3. Angelieri F, Sousa MVdS, Kanashiro LK, Siqueira DF, Maltagliati LÁ.Effects of low intensity laser on pain sensitivity during orthodontic movement. Dental Press J Orthod 2011;16:95-102.

4. Arias OR, Marquez-Orozco MC.Aspirin, acetaminophen, and ibuprofen: their effects on orthodontic tooth movement. Am J Orthod Dentofacial Orthop 2006;130:364-70.

5. Walsh L. The current status of laser applications in dentistry. Aust Dent J 2003;48:146-55.

6. He W, Li C, Liu Z, Sun J, Hu Z, Yin X, et al.Efficacy of low-level laser therapy in the management of orthodontic pain: a systematic review and meta-analysis. Lasers Med Sci 2013;28:1581-9.

7. Qamruddin I, Alam MK, Fida M, Khan AG. Effect of a single dose of low-level laser therapy on spontaneous and chewing pain caused by elastomeric separators. Am J Orthod Dentofacial Orthop 2016;149:62-6.

8. Cepera F, Torres FC, Scanavini MA, Paranhos LR, Capelozza Filho L, Cardoso MA, et al.Effect of a low-level laser on bone regeneration after rapid maxillary expansion. Am J Orthod Dentofacial Orthop 2012;141:444-50.

9. Gkantidis N, Mistakidis I, Kouskoura T, Pandis N.Effectiveness of non-conventional methods for accelerated orthodontic tooth movement: a systematic review and meta-analysis. J Dent 2014;42:1300-19.

10. Deana NF, Zaror C, Sandoval P, Alves N.Effectiveness of low-level laser therapy in reducing orthodontic pain: A Systematic Review and Meta-Analysis. Pain Res Manag 2017;2017.
11. Gok F, Buyuk SK, Ozkan S, Benkli YA.Comparison of arch width and depth changes and pain/discomfort with conventional and copper $\mathrm{Ni}-\mathrm{Ti}$ archwires for mandibular arch alignment. J World Fed Orthod 2018;7:24-8.

12. Qamruddin I, Alam MK, Mahroof V, Fida M, Khamis MF, Husein A.Effects of low-level laser irradiation on the rate of orthodontic tooth movement and associated pain with self-ligating brackets. Am J Orthod Dentofacial Orthop 2017;152:622-30.

13. Qamruddin I, Alam MK, Abdullah H, Kamran MA, Jawaid N, Mahroof V.Effects of single-dose, low-level laser therapy on pain associated with the initial stage of fixed orthodontic treatment: A randomized clinical trial. Korean J Orthod 2018;48:90-7.

14. Jensen M, Karoly P, Braver S.The measurement of clinical pain intensity: a comparison of six methods. Pain 1986;27:117-26.

15. Joyce C, Zutshi D, Hrubes V, Mason R.Comparison of fixed interval and visual analogue scales for rating chronic pain. Eur J Clin Pharmacol 1975;8:415-20.

16. Seymour R, Simpson J, Charlton J, Phillips M.An evaluation of length and end-phrase of visual analogue scales in dental pain. . Pain 1985;21:177- 85 .

17. Price D, McGrath P, Rafii A, Buckingham B.The validation of visual analogue scales as ratio scale measures for chronic and experimental pain. Pain 1983:17:45-56.

18. Abtahi SM, Mousavi SA, Shafaee H, Tanbakuchi B.Effect of low-level laser therapy on dental pain induced by separator force in orthodontic treatment. Dent res j 2013;10:647.

19. AlSayed HM, Sultan K, Hamadah O.Evaluating low-level laser therapy effect on reducing orthodontic pain using two laser energy values: a split-mouth randomized placebo-controlled trial. Eur J Orthod 2017.

20. Furquim RD, Pascotto RC, Rino Neto J, Cardoso JR, Ramos AL.Low-level laser therapy effects on pain perception related to the use of orthodontic elastomeric separators. Dental Press J Orthod 2015;20:37-42.

21. Lim H-M, Lew KK, Tay DK.A clinical investigation of the efficacy of low level laser therapy in reducing orthodontic postadjustment pain. Am J Orthod Dentofacial Orthop 1995; 108:614-22.

22. Dalaie K, Hamedi R, Kharazifard MJ, Mahdian M, Bayat M.Effect of low-level laser therapy on orthodontic tooth movement: a clinical investigation. J dent (Tehran, Iran) 2015;12:249-56. 
23. Heravi F, Moradi A, Ahrari F.The effect of low level laser therapy on the rate of tooth movement and pain perception during canine retraction. Oral Health Dent Manag 2014;13:183-8.

24. Almallah MM, Almahdi WH, Hajeer MY.Evaluation of low level laser therapy on pain perception following orthodontic elastomeric separation: a randomized controlled trial. J Clin Diagn Res 2016;10:23.

25. Artés-Ribas M, Arnabat-Dominguez J, Puigdollers A.Analgesic effect of a low-level laser therapy $(830 \mathrm{~nm})$ in early orthodontic treatment. Lasers Dent Sci 2013;28:335-41.

26. Bicakci AA, Kocoglu-Altan B, Toker H, Mutaf I, Sumer Z.Efficiency of low-level laser therapy in reducing pain induced by orthodontic forces. Photomed Laser Surg 2012;30:460-5.

27. Eslamian L, Borzabadi-Farahani A, Hassanzadeh-Azhiri A, Badiee MR, Fekrazad R. The effect of 810-nm low-level laser therapy on pain caused by orthodontic elastomeric separators. Lasers Med Sci 2014;29:559-64.

28. Farias RD, Closs LQ, Miguens Jr SAQ.Evaluation of the use of low-level laser therapy in pain control in orthodontic patients: A randomized split-mouth clinical trial. Angle Orthod 2015;86:193-8.

29. Marini I, Bartolucci ML, Bortolotti F, Innocenti G, Gatto MR, Bonetti GA.The effect of diode superpulsed low-level laser therapy on experimental orthodontic pain caused by elastomeric separators: a randomized controlled clinical trial. Lasers med sci 2015;30:35-41.
30. Nóbrega C, da Silva EMK, de Macedo CR. Low-level laser therapy for treatment of pain associated with orthodontic elastomeric separator placement: a placebo-controlled randomized double-blind clinical trial. Photomed Laser Surg 2013;31:10-6.

31. Bayani S, Rostami S, Ahrari F, Saeedipouya I.A randomized clinical trial comparing the efficacy of bite wafer and low level laser therapy in reducing pain following initial arch wire placement. Laser therapy 2016;25:121-9.

32. Deshpande P, Patil K, Mahima V, Shivalinga B, Suchetha M, Ranjan A. Low-level laser therapy for alleviation of pain from fixed orthodontic appliance therapy: a randomized controlled trial. Journal of Advanced Clinical \& Research Insights 2016;3:43-6.

33. Tortamano A, Lenzi DC, Haddad AC, Bottino MC, Dominguez GC, Vigorito JW. Low-level laser therapy for pain caused by placement of the first orthodontic archwire: a randomized clinical trial. Am J Orthod Dentofacial Orthop 2009;136:662-7.

34. Domínguez A, Velásquez SA. Effect of low-level laser therapy on pain following activation of orthodontic final archwires: a randomized controlled clinical trial. Photomed Laser Surg 2013;31:36-40.

35. Doshi-Mehta G, Bhad-Patil WA.Efficacy of low-intensity laser therapy in reducing treatment time and orthodontic pain: a clinical investigation. Am J Orthod Dentofacial Orthop 2012;141:289-97. 